\begin{tabular}{|c|l|}
\hline Title & Time resolved measurements of water-soluble organic carbon in Tokyo \\
\hline Author(s) & $\begin{array}{l}\text { Miyazaki, Y.; Kondo, Y.; Takegawa, N.; Komazaki, Y.; Fukuda, M.; Kawamura, K.; Mochida, M.; Okuzawa, K.; } \\
\text { Weber, R. J. }\end{array}$ \\
\hline Citation & $\begin{array}{l}\text { Journal of Geophysical Research, 111, D23206 } \\
\text { https://doi.org/10.1029/2006JD007125 }\end{array}$ \\
\hline Issue Date & 2006-12-12 \\
\hline Doc URL & http://hdl.handle.net/2115/26152 \\
\hline Rights & $\begin{array}{l}\text { An edited version of this paper was published by A GU. Copyright 2006, American Geophysical Union, JOURNAL OF } \\
\text { GEOPHY SICAL RESEARCH-ATMOSPHERES, 111. }\end{array}$ \\
\hline Type & article (author version) \\
\hline File Information & JGRA 111.pdf \\
\hline
\end{tabular}

Instructions for use 


\section{Time-resolved measurements of water-soluble organic carbon in Tokyo}

Y. Miyazaki, Y. Kondo, N. Takegawa, Y. Komazaki, and M. Fukuda

Research Center for Advanced Science and Technology, University of Tokyo, Tokyo, Japan

K. Kawamura, M. Mochida and K. Okuzawa

Institute of Low Temperature Science, Hokkaido University, Sapporo, Japan

R. J. Weber

School of Earth and Atmospheric Sciences, Georgia Institute of Technology,

Atlanta, Georgia, USA

Short title: WSOC IN TOKYO

Submitted to J. Geophys. Res. on January 26, 2006

Revised on 25 May, 2006 
Abstract. Semicontinuous measurements of water-soluble organic carbon (WSOC) and hourly measurements of organic carbon (OC) and elemental carbon (EC) in $\mathrm{PM}_{1}$ were conducted in the urban area of Tokyo in winter, summer, and fall 2004. The measurements of WSOC were made every 6 min using a particle-into-liquid sampler (PILS) with a total organic carbon (TOC) analyzer. Overall, the PILS and 12-hr integrated filter measurements of WSOC agreed to within $12 \%$. The WSOC concentrations and WSOC/OC ratio had diurnal variations with peaks at 1200-1400 LT in summer and in the afternoon in winter. On average, the WSOC/OC ratio was $20 \%$ in winter and $35 \%$ during summer and late fall in terms of carbon. The difference in the winter and summer frequency distributions of the WSOC/OC ratio suggests that the sampled air masses in summer and fall were more photochemically processed than those in winter. Secondary organic carbon (SOC) concentrations were estimated using the EC-tracer method. The measured WSOC showed highly positive correlations with those of the derived SOC $\left(r^{2}=0.61-0.79\right)$ with WSOC/SOC slopes of 0.67 to 0.75 for each season. These results suggest that most of the measured WSOC in this study was associated with most of the SOC. The average water-insoluble organic carbon (WIOC)/EC ratios observed in Tokyo were nearly constant $(1.1 \pm 0.1)$ throughout the periods. WIOC showed positive correlations with $\mathrm{EC}$ and $\mathrm{CO}$, indicating that motor vehicle emissions significantly contributed to the observed WIOC. 


\section{Introduction}

Organic compounds constitute a major fraction $(10-70 \%)$ of total fine particle mass in urban air [e.g., Turpin et al, 2000]. Previous studies have shown that water-soluble organic carbon (WSOC) can significantly alter the hygroscopic property of aerosols and may be important in determining the ability of particles to act as cloud condensation nuclei (CCN) [Novakov and Penner, 1993; Saxena et al., 1995, Facchini et al., 1999]. Therefore, WSOC can play an important role both in direct and indirect effects of radiative forcing in the troposphere. WSOC is also considered to be associated with a major fraction of secondary organic aerosol (SOA), which is formed by oxidation of volatile organic compounds (VOCs) followed by condensation on existing particles and/or nucleation. Warneck [2003] has recently suggested that oxalic acid, which is generally the most abundant dicarboxylic acid in the atmosphere [Kawamura and Sakaguchi, 1999], may be formed in cloud droplets through heterogeneous reactions in marine environments. Knowledge of the relative abundance of WSOC provides insight into processes leading to SOA as well as $\mathrm{CCN}$, which have important implications for regional air quality and global climate.

Measurement of the water-soluble fraction of total organic carbon provides valuable clues regarding the chemistry of organic aerosol and its interaction with water vapor in ambient air [Saxena and Hildemann, 1996; Jacobson et al., 2000]. Zappoli et al. [1999] found that WSOC in fine particle $\left(D_{p}<1.5 \mu \mathrm{m}\right)$ accounted for 77 and $65 \%$ of the fine particle organic carbon (OC) in European background and polluted sites, respectively. Seasonal variation in fine particles in the Po Valley, Italy, showed that WSOC accounted for between $38 \%$ in winter and $50 \%$ in summer of OC [Decesari et al., 2001]. These measurements were made by integrated filter-based samplings (typically 12-24 hrs) followed by off-line chemical analysis. Sullivan et al. [2004] first made online measurements of WSOC and found that the 
average WSOC in a residential area of St. Louis, MO, contributed to 64,61 , and $31 \%$ of OC in June, August, and October, respectively.

Decesari et al. [2000] has proposed that WSOC can be separated into three main classes according to the following acid/base characters: neutral compounds, mono-/di-carboxylic acids, and polyacids. Previous studies have also shown that a considerable portion of WSOC is composed of polyacidic compounds or humic-like substances (HULIS) [e.g., Havers et al., 1998; Kiss et al., 2002; Mayol-Bracero et al., 2002]. Observational studies of WSOC have focused mainly on dicarboxylic acids, keto acids, and dicarbonyls. For urban aerosols, e.g., these include $\mathrm{C}_{2}-\mathrm{C}_{9} \alpha, \omega$-dicarboxylic acids; $\mathrm{C}_{2}-\mathrm{C}_{9} \alpha$-oxo-carboxylic acids; pyruvic acid; and $\mathrm{C}_{2}-\mathrm{C}_{3}$ dicarboxylic acids [e.g., Sempere and Kawamura, 1994].

Experimental data on WSOC in the ambient air, however, are still lacking, especially in urban regions, and the behavior of WSOC is not well characterized since emission, production, and transport processes of aerosol have dynamic timescales ranging from minutes to hours. This situation emphasizes the need for time-resolved aerosol measurements, which provide data that leads to a much better understanding of the chemical properties of WSOC. Moreover, it is generally believed that under certain conditions, (e.g., lack of biomass burning influence), total SOA is nearly equivalent to WSOC because SOA produces oxygenated functional groups resulting in $\mathrm{OC}$ that is water soluble, although this has not been experimentally demonstrated for ambient air.

This paper presents the results of high time-resolution measurements of WSOC, OC, and EC from the Tokyo metropolitan area during the winter, summer, and fall of 2004. The results are interpreted in terms of the properties of WSOC and its related parameters in urban Tokyo, including their diurnal and seasonal profiles. We also present the relationship between WSOC and estimated secondary OC (SOC) estimated based on the EC-tracer 
method.

\section{Experiments}

Measurements were made on the top floor of a building ( $20 \mathrm{~m}$ above ground level and $55 \mathrm{~m}$ above sea level) on the campus of the Research Center for Advanced Science and Technology (RCAST), University of Tokyo $\left(35.4^{\circ} \mathrm{N}, 139.4^{\circ} \mathrm{E}\right)$. The observation site is located $\sim 8 \mathrm{~km}$ west of the center of Tokyo and $\sim 20 \mathrm{~km}$ northwest of the coast (Tokyo Bay). Further details on the sampling location and meteorological conditions are described elsewhere [Kondo et al., 2006a; Takegawa et al., 2006]. The simultaneous measurements of WSOC, OC, and elemental carbon (EC) were made during three periods: 25 January-6 February 2004 (winter), 1-17 August 2004 (summer), and 3-18 November 2004 (fall).

\subsection{PILS-WSOC}

Semicontinuous measurements of WSOC were made using a particle-into-liquid sampler (PILS) [Weber et al., 2001; Orsini et al., 2003] followed by online quantification of TOC every 6 min using a total organic carbon (TOC) analyzer (Model 810; Sievers, Boulder, CO). Because Sullivan et al. [2004] have presented the principles and details of PILS-WSOC operation, only a brief description is given here. Ambient aerosol was sampled at a flow rate of $16.7 \mathrm{~L} \mathrm{~min}^{-1}$ by the PILS, which used a steam saturator to grow the aerosol to sizes that can be collected by inertial impaction. The liquid sample $\left(1.3 \mathrm{ml} \mathrm{min}^{-1}\right)$ was filtered by a $0.5-\mu \mathrm{m}$ stainless steel meshed liquid filter. The carbonaceous compounds in the liquid sample were then quantified online with the TOC analyzer. In the TOC analyzer, organic compounds dissolved in deionized water were oxidized to form carbon dioxide $\left(\mathrm{CO}_{2}\right)$ using an ultraviolet (UV) lamp and ammonium persulfate as a chemical oxidizing agent. The $\mathrm{CO}_{2}$ formed was 
then measured using a membrane-based conductivity detection technique. The term WSOC in the present study is technically defined as particles sampled by the PILS and detected by the TOC analyzer after penetrating the liquid filter.

Measurements of carbonaceous aerosol are difficult due to possible interferences from the following two types of interactions with vapor phase compounds: adsorption of VOCs that contribute to the aerosol measurements (positive artifact) and volatilization of semi-VOCs during the sampling (negative artifact). In order to reduce the positive artifact, a parallel plate diffusion denuder [Eatough et al., 1993] was placed upstream of the PILS. For the negative artifact, evaporative losses of semi-VOCs during the PILS sampling have not been evaluated in this study.

Internal calibration was periodically performed using oxalic acid as a standard. The concentrations of dissolved TOC into water ranged between 30 and $230 \mathrm{ppb}$ in the present study. The zero levels (blanks) of WSOC were measured automatically for $30 \mathrm{~min}$ every $4 \mathrm{hr}$ by passing the sample air through a Teflon ${ }^{\circledR}$ filter upstream of the PILS. The uncertainty in the WSOC measurements in this study was estimated to be between \pm 5 to $9 \%$. A $\mathrm{PM}_{1}$ (1.0- $\mu$ m-diameter cutoff size) cyclone (URG-2000-30EHB; URG Corp., Chapel Hill, NC) was used during the measurement period.

\subsection{Comparisons to Integrated Filter Measurements}

The traditional technique for measuring WSOC is manual extraction of collected mass from filters using purified water. In addition to the WSOC measurements by the PILS, 12-hr integrated filter samples were taken to determine WSOC concentrations and provide a comparison of the two techniques during the period from 9 to 15 August 2004. A $\mathrm{PM}_{1}$ cyclone (URG-2000-30EHB; URG Corp.) and Teflon ${ }^{\circledR}$ filter pack (URG-2000-30FG; URG 
Corp.) was used for the filter sampling. The sampling was made at a flow rate of $16.7 \mathrm{~L} \mathrm{~min}^{-1}$. We did not use a carbon denuder during the sampling. The quartz filters were extracted with organic-free ultrapure water. The water extracts were then filtered with a syringe disk filter (Miller-GV, $0.22 \mu \mathrm{m}$; Millipore, Billerica, MA), which had been rinsed under ultrasonication in pure water three times and then flushed with pure water five times to remove potential contaminants. The WSOC in the water extracts was measured using a Shimadzu (Kyoto) TOC-5000A carbon analyzer [Wang et al, 2005]. The analytical error of this measurement was $15 \%$ with a detection limit of $0.1 \mu \mathrm{gC} \mathrm{m} \mathrm{m}^{-3}$.

Figure 1a shows the comparison of WSOC measured by the PILS together with WSOC data obtained by the filter sampling (Filter-WSOC). The PILS-WSOC captured the short-term temporal variations of WSOC that were averaged in the Filter-WSOC. For quantitative comparison, individual PILS-WSOC data were merged into the 12-hr filter sampling periods and the merged data are plotted against the Filter-WSOC (Figure 1b). The PILS-WSOC regression slope to the integrated Filter-WSOC (forced through zero) was $0.88 \pm 0.10\left(\mathrm{r}^{2}=0.89 ; 95 \%\right.$ confidence interval). Overall, concentrations of PILS-WSOC agreed well with those of Filter-WSOC to within $12 \%$. The result showed that the PILS-WSOC measurements in the current study were almost identical to the filter-based measurements of WSOC. Slightly lower PILS-WSOC measurements may be involved with several factors, including sampling artifacts associated with each measurement (e.g., absorption of volatile organic compounds that contributed to the particle sampling), differences in the solubility of various organic compounds, and differences in the analytical method of TOC. However, these possible factors were not evaluated in the current study. Sullivan and Weber [2006b] also compared the PILS-WSOC measurements to 24-hr integrated High-Volume filter measurements in Atlanta, GA. They reported that the 
High-Volume samplers were generally higher than the PILS-WSOC measurements by $10 \%$, which is similar to the results obtained in this study.

\subsection{OC and EC Measurements}

Mass concentrations of $\mathrm{OC}$ and EC were measured using a semicontinuous EC/OC analyzer (Sunset Laboratory Inc., Tigard, OR) [Birtch and Cary, 1996; Bae et al., 2004]. The inlet for air sampling was equipped with a $\mathrm{PM}_{1}$ cyclone (Model URG-2000-30EHB; URG Inc.) and denuder that is identical to that used for measuring WSOC. In this instrument, ambient aerosol particles are collected on a quartz-fiber filter for $45 \mathrm{~min}$ at a flow rate of $8 \mathrm{~L}$ $\min ^{-1}$, followed by analysis based on the thermal-optical-transmittance method for 15 min. Our measurements of $\mathrm{PM}_{1}$ and $\mathrm{PM}_{2.5}$ prior to this study showed that on average the mass of OC and $\mathrm{EC}$ in $\mathrm{PM}_{1}$ accounted for $75 \%$ and $95 \%$ of those in $\mathrm{PM}_{2.5}$, respectively, at the same sampling site (Komazaki et al., unpublished data). This result shows that the size distributions of $\mathrm{OC}$ and $\mathrm{EC}$ were dominated by $\mathrm{PM}_{1}$ at the sampling site.

In the present work, we used the temperature protocol proposed by the National Institute for Occupational Safety and Health (NIOSH) [Birch and Cary, 1996]. Part of the OC was pyrolytically converted to EC as the filter was heated in an oxygen-free helium atmosphere in four temperature steps up to $870^{\circ} \mathrm{C}$. After completion of the oxygen-free heating stages, the filter was heated to $900^{\circ} \mathrm{C}$ in the presence of $2 \%$ oxygen. At this stage, both the original EC and that produced by pyrolysis of $\mathrm{OC}$ were converted to $\mathrm{CO}_{2}$, which was measured by a non-dispersive infrared (NDIR) $\mathrm{CO}_{2}$ detector. Correction for the pyrolytic conversion of OC to EC was performed by monitoring the transmittance of a pulsed $\mathrm{He}-\mathrm{Ne}$ diode laser beam at $670 \mathrm{~nm}$ through the quartz-fiber filter during the sample analysis. Background levels of OC were periodically checked by placing a particle filter upstream of the denuder. 
The overall accuracy of OC and EC measurements were 16 and 6\%, respectively, for the study period [Kondo et al., 2006a; Takegawa et al., 2005]. The detection limits of these measurements were also assessed as $1 \mu \mathrm{g} \mathrm{m}^{-3}$ for OC and $0.2 \mu \mathrm{g} \mathrm{m}^{-3}$ for EC. Water-insoluble organic carbon (WIOC) is defined as WIOC $=$ OC - WSOC. The uncertainty of WIOC was estimated to be $26 \%$, by combining errors of the OC and WSOC measurements. This paper reports 1-hr average OC, EC, and WIOC concentrations.

\section{4. $\mathrm{NO}_{\mathrm{x}}, \mathrm{NO}_{\mathrm{y}}, \mathrm{CO}$, and $\mathrm{O}_{3}$}

Nitrogen oxides $\left(\mathrm{NO}_{\mathrm{x}}=\mathrm{NO}+\mathrm{NO}_{2}\right)$, total reactive nitrogen $\left(\mathrm{NO}_{\mathrm{y}}\right)$, and carbon monoxide (CO) were simultaneously measured in this study to determine primary combustion-generated carbon emissions. Measurments of $\mathrm{NO}_{\mathrm{x}}$ and $\mathrm{NO}_{\mathrm{y}}$ were conducted using a $\mathrm{NO}-\mathrm{O}_{3}$ chemiluminescence detector combined with a photolytic converter and a gold tube converter with a time resolution of $1 \mathrm{~s}$ [Kondo et al., 1997]. The accuracy of the measurements of $\mathrm{NO}, \mathrm{NO}_{2}$, and $\mathrm{NO}_{\mathrm{y}}$ were 10,16 , and $12 \%$, respectively (Fukuda et al., manuscript in preparation).

An NDIR gas analyzer (Model 48; Thermo Environmental Instruments (TEI), Franklin, $\mathrm{MA}$ ) was used to measure $\mathrm{CO}$ at an integration time of $1 \mathrm{~min}$. The detection limit for $\mathrm{CO}$ was 10 parts per billion by volume (ppbv). The overall precision and accuracy of the 1-min $\mathrm{CO}$ measurements were estimated to be $4 \mathrm{ppbv}$ and $20 \mathrm{ppbv}$, respectively, at a $\mathrm{CO}$ mixing ratio of 400 ppbv [Takegawa et al., 2006]. Ozone was measured using the UV absorption technique with an integration time of $1 \mathrm{~min}$ (Model 1101; Dylec, Tokyo). All of these gas-phase data as well as WSOC were merged into the time interval of OC and EC sampling ( $\sim 45 \mathrm{~min}$ ).

\subsection{Estimation of Primary and Secondary OC}


To compare the measured WSOC with secondary OC (SOC), we estimated primary OC (POC) and SOC by using the measured EC and OC following the EC-tracer method [e.g., Turpin and Huntzicker, 1995]. EC is often used as a good tracer of primary combustion-generated carbon emissions [e.g., Turpin and Huntzicker, 1991]. The EC-tracer method assumes a representative ratio of primary $\mathrm{OC} / \mathrm{EC}$ for a given area because $\mathrm{EC}$ and primary OC typically have the same sources. By this method, POC concentrations ([POC]) can be defined as

$$
[\mathrm{POC}]=[\mathrm{OC} / \mathrm{EC}]_{\text {prim }} \times[\mathrm{EC}]+c
$$

where $[\mathrm{OC} / \mathrm{EC}]_{\text {prim }}$ is an estimated primary $\mathrm{OC} / \mathrm{EC}$ ratio and $c$ is to account for other sources, such as noncombustion, that contributed to the POC, and sampling artifacts [Turpin and Huntzicker, 1995; Strader et al., 1999]. The SOC concentration [SOC] can be estimated as

$$
[\mathrm{SOC}]=[\mathrm{OC}]-[\mathrm{POC}]
$$

where $[\mathrm{OC}]$ is the measured $\mathrm{OC}$ concentration.

As a first step in determining $[\mathrm{OC} / \mathrm{EC}]_{\text {prim }}$, we identified the data representing ambient concentrations dominated by primary emissions. We selected the data in which the EC concentrations were larger than $0.5 \mu \mathrm{g} \mathrm{m}^{-3}$. In the present study, $\mathrm{NO}_{\mathrm{x}} / \mathrm{NO}_{\mathrm{y}}$ ratios and $\mathrm{CO}$ were used as tracers of combustion-related primary emissions. The inverse of this ratio is also a good indicator of the photochemical processing of an air mass. Our data showed that as $\mathrm{NO}_{\mathrm{x}} / \mathrm{NO}_{\mathrm{y}}$ ratios increased, $\mathrm{OC} / \mathrm{EC}$ ratios tended to decrease, indicating a greater influence from primary emissions over the study area (data not shown). CO concentrations were also 
used as an indicator of the effect of mixing with surrounded air. We selected $\mathrm{NO}_{\mathrm{x}} / \mathrm{NO}_{\mathrm{y}}$ and CO levels larger than a certain criteria for each season to determine the periods when OC concentrations were influenced by primary emissions. As shown in Table 1, we selected a dataset in which $\mathrm{NO}_{\mathrm{x}} / \mathrm{NO}_{\mathrm{y}}$ ratios were larger than $0.9(0.8)$ for winter (summer) and $\mathrm{CO}$ levels larger than $700 \mathrm{ppbv}$ (400 ppbv) for winter (summer). The criteria of $\mathrm{NO}_{\mathrm{x}} / \mathrm{NO}_{\mathrm{y}}$ levels are approximately the medians and those of CO levels are the highest $80 \%$ values in each season. The higher criteria of $\mathrm{NO}_{\mathrm{x}} / \mathrm{NO}_{\mathrm{y}}$ ratios in winter than summer is due to lower concentrations of $\mathrm{OH}$, which leads to longer lifetime of $\mathrm{NO}_{\mathrm{x}}$ in winter. Takegawa et al. [2006] estimated the diurnally averaged $\mathrm{NO}_{\mathrm{x}}$ lifetime of $\sim 1.3$ days in winter and $\sim 0.6$ days in summer for the same sampling site. In addition, the lower criteria of CO concentrations in summer are due to more effective vertical mixing of air within the boundary layer. The higher boundary layer height in summer leads to more effective dilution of air and lowering the $\mathrm{CO}$ concentrations near the surface compared to winter [Kondo et al., 2006a].

From this data set, the lowest $50 \%$ of $\mathrm{OC} / \mathrm{EC}$ ratios were selected to represent the ambient concentrations dominated by primary emissions. Linear regression of OC - EC by least squares minimization was then fitted to the datasets of the primary concentrations. This slope represents the $[\mathrm{OC} / \mathrm{EC}]_{\text {prim }}$ in equation (1), which was then used to estimate SOC by equation (2). The noncombustion term " $c$ " in equation (1) was assumed to be zero in this study, due to the small intercept for the lowest $50 \%$ of OC/EC values.

Table 1 summarizes the estimated $[\mathrm{OC} / \mathrm{EC}]_{\text {prim }}$ ratio, and other parameters for each season. Scatter plots of OC versus EC are also shown in Figure 2 showing the estimated primary OC and EC concentrations, and all measurement data for each study period. The estimated ratios of $[\mathrm{OC} / \mathrm{EC}]_{\text {prim }}$ were $1.46 \pm 0.12,1.36 \pm 0.12$, and $1.33 \pm 0.13 \mu \mathrm{gC} \mathrm{m}{ }^{-3}(\mu \mathrm{gC}$ $\left.\mathrm{m}^{-3}\right)^{-1}$ for winter, summer, and fall, respectively, with $95 \%$ confidence intervals. Streets et al. 
[2003] estimated emission ratios of OC/EC from anthropogenic sources to be $1.40 \mathrm{~g} \mathrm{~g}^{-1}$ over Japan for the year 2000. The estimated $[\mathrm{OC} / \mathrm{EC}]_{\text {prim }}$ in the current study was similar to the OC/EC emission ratio from Streets et al., although the uncertainty in their emission ratio was large (83\% for EC and $181 \%$ for OC at $95 \%$ confidence intervals). Cabada et al. [2004] applied the EC tracer method to estimate POC and SOC during summer near downtown Pittsburgh, PA, by introducing $\mathrm{NO}, \mathrm{NO}_{\mathrm{x}}$, and $\mathrm{CO}$ as combustion-related tracers. They used measurements (with time resolutions of 2-6 hr) of $\mathrm{OC}$ and $\mathrm{EC}$ to derive $[\mathrm{OC} / \mathrm{EC}]_{\text {prim }}$ of $1.70 \pm 0.20$, a result that is similar to but slightly higher than the current estimate.

We now examine possible uncertainties in the estimation of POC and SOC mass concentrations. Uncertainties were mainly introduced by assumptions that primary noncombustion $\mathrm{OC}$ was negligible and that $[\mathrm{OC} / \mathrm{EC}]_{\text {prim }}$ was constant for each season. First, if primary noncombustion (e.g., biogenic) OC had substantially contributed to SOC levels, the SOC concentrations derived here will be overestimated. Considering the intercept from the linear regression fit in Figure 2, the non-EC associated POC would be $0.3,0.1$, and $0.1 \mu \mathrm{gC}$ $\mathrm{m}^{-3}$ for the winter, summer, and fall periods, respectively. These values would lead to lower mean SOC concentrations by $7 \%$ (winter) and $<1 \%$ (summer and fall) than the present estimated values. Second, variation of the source strength and local meteorology can change the $[\mathrm{OC} / \mathrm{EC}]_{\text {prim }}$ even within a few hours to 1 day [Harley et al., 2005]. The uncertainties of $[\mathrm{OC} / \mathrm{EC}]_{\text {prim }}(95 \%$ confidence intervals) correspond to $\pm 10-12 \%$ of the SOC concentrations for the entire periods estimated above. Overall, these considerations suggest possible uncertainties of $\pm 19 \%$ for the SOC estimated in this study.

It is important to note that combustion sources emit hydrophobic EC and then become hydrophilic with time scales of about 0.3-1.2 days [e.g., Cooke et al., 1999; Riemer et al., 2004], followed by being removed by clouds or precipitation scavenging (rainout). However, 
cloud formation near the surface in Tokyo was not frequent and time scales of submicron EC removal due to rainout is estimated to be $>4$ days [Kondo et al., 2006a]. Therefore, the effect of EC removal on the determination of $[\mathrm{OC} / \mathrm{EC}]_{\text {prim }}$ can be neglected in this study. Quantitative comparisons of the derived SOC and the measured WSOC concentrations are made in section 3.3 .

\section{Results and Discussion}

\subsection{Temporal Variations}

Figure 3 shows time series plots of the measured WSOC, OC, and EC mass concentrations for the winter, summer, and fall periods. The time series provides insights into the range in mass concentrations of these species during the study periods and the amount of data available for each measurement. Mean values of WSOC, WIOC, OC, EC, and the ratio of WSOC to OC for the three study periods are also summarized in Table 2. Throughout the study periods, temporal trends of the WSOC levels were similar to those of the OC levels. The WSOC concentrations ranged from levels below the detection limits to maximum values of approximately 5,8 , and $10 \mu \mathrm{gC} \mathrm{m} \mathrm{m}^{-3}$ for the winter, summer, and fall periods, respectively. The OC concentrations ranged between 2 and $15 \mu \mathrm{gC} \mathrm{m}{ }^{-3}$ (winter), 0.2 and $13 \mu \mathrm{gC} \mathrm{m}{ }^{-3}$ (summer), and 1 and $23 \mu \mathrm{gC} \mathrm{m}{ }^{-3}$ (fall). Diurnal variations of WSOC, OC, WSOC/OC, WIOC, $\mathrm{EC}$ and $\mathrm{CO}$ for the winter and summer periods are also shown in Figure 4. Diurnal variations for the fall are not shown because the sampling site was affected by synoptic-scale meteorology (at a time scale of 3 to 5 days) in fall, and there was no distinct diurnal change. The properties of WSOC and its related parameters in their temporal profiles are summarized below.

In winter, the highest WSOC and OC concentrations reached 5 and $16 \mu \mathrm{gC} \mathrm{m}{ }^{-3}$, 
respectively, on 2 February (Figure 3a). On this day, a surface low was developing just south of the Japanese main island of Honshu. The sampling site was located behind a surface cold front associated with the low pressure system. The prevailing local surface wind at the sampling site was northerly with an average wind speed of $2 \mathrm{~m} \mathrm{~s}^{-1}$, causing a transport of pollutants inland from the Kanto Plain. For diurnal variations (Figure 4), WSOC began to increase at $\sim 0600 \mathrm{LT}$, reaching maximum concentrations of $\sim 1 \mu \mathrm{gC} \mathrm{m} \mathrm{m}^{-3}$ in the late afternoon (1400-1800 LT). Moreover, a second peak in WSOC was observed at night (2200-2400 LT). The WSOC/OC ratios in winter had maximum values of $20 \%$ at $\sim 1600$ to $1800 \mathrm{LT}$ and minimum values of $13 \%$ at $\sim 0600 \mathrm{LT}$; these trends resembled the WSOC trends.

In summer, large enhancements of these species were especially observed from 12 to 14 August (Figure 3b). During this period, the wind speed was relatively week $\left(<2 \mathrm{~m} \mathrm{~s}^{-1}\right)$, and the weather was fairly clear. The $\mathrm{OC} / \mathrm{EC}$ ratios were relatively high at 2 to 7 , with maximum $\mathrm{O}_{3}$ concentrations exceeding $100 \mathrm{ppbv}$, indicating high photochemical activity during this period. The median WSOC concentrations started to increase in the early morning $(\sim 0400$ LT), showing broad peaks of $\sim 1.1 \mu \mathrm{gC} \mathrm{m} \mathrm{m}^{-3}$ at $\sim 0800$ to $1400 \mathrm{LT}$ (Figure 4 ). The daytime peak values were $\sim 2-3$ times larger than values during the night. The diurnal trends of OC also showed broad peaks at 0800 to $1400 \mathrm{LT}$ with maximum values of $3.0 \mu \mathrm{gC} \mathrm{m} \mathrm{m}^{-3}$; these trends were similar to the WSOC trends. The WSOC/OC ratios had a maximum value of $45 \%$ at 1200 to $1400 \mathrm{LT}$ and a minimum value of $30 \%$ at 0000 to $0200 \mathrm{LT}$.

The observed WSOC levels could be interpreted as a combination of locally produced WSOC and previously produced WSOC transported from an upwind region. To examine the relative degree of photochemical processing, the WSOC/EC ratios can be compared to $\mathrm{O}_{3}$ without the effect of dilution in the observed air masses. During summer, the WSOC/EC ratio correlated well with $\mathrm{O}_{3}\left(\mathrm{r}^{2}=0.62\right)$. When the daytime data were selected, the $\mathrm{r}^{2}$ value 
became much higher $\left(r^{2}=0.72\right)$. Therefore, a major fraction of WSOC in summer was likely produced via similar photochemical processes responsible for $\mathrm{O}_{3}$ production. Kawamura and Yasui [2005] measured water-soluble organics (diacids, ketoacids, and dicarbonyls) in the Tokyo metropolitan area on 6 days in summer and winter of 1989; these organic compounds accounted for $<2.5 \%$ of the total carbon. Despite the limited number of samples, they also showed diurnal variations of these species with a maximum during the day, which were interpreted as the photo-oxidation of aromatic hydrocarbons and cyclic olefins. In contrast, in winter, relatively higher values of WSOC and OC from the late afternoon until midnight were likely a result of the accumulation of these species due to the lower boundary layer height in wintertime. In addition, a poor correlation between the WSOC/EC ratio and $\mathrm{O}_{3}\left(\mathrm{r}^{2}<0.01\right)$ existed. These results suggest that elevated WSOC levels in winter were unlikely due to local production at the sampling site.

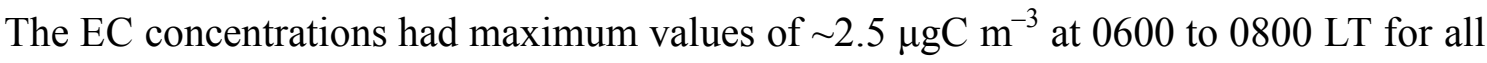
the seasons. A morning peak in EC concentrations has been typically observed in urban areas [e.g., Turpin and Huntzicker, 1991; Allen et al., 1999; Kondo et al., 2006a]. Kondo et al. [2006a] discussed these diurnal variations in EC observed at the same observatory, showing that exhaust from diesel engines was a major EC source in Tokyo. The decrease in the concentrations of EC as well as WSOC and OC in the afternoon in summer can be explained by the high wind speed caused by the development of a sea breeze and an increase in the boundary layer height. These factors could lead to effective vertical mixing of overlying air with lower concentrations of these species, as discussed in Kondo et al. [2006a].

\subsection{Seasonal Differences in WSOC/OC Ratios}

Figure 5 shows frequency distributions of the WSOC/OC ratios during the winter, 
summer, and fall periods. Overall, the observed WSOC/OC ratios ranged from 2 to $80 \%$. A seasonal difference in the modal ratios is apparent. The WSOC/OC ratios were $2-45,2-86$, and $5-85 \%$ for the winter, summer, and fall periods, respectively. Median WSOC/OC ratios were $19 \%$ in winter and $35 \%$ in summer and fall in terms of carbon. Considering that the average WSOC levels in summer and fall were also higher than those in winter, the results suggest that the sampled air masses in summer and fall were more photochemically processed than those in winter. Moreover, the WSOC/OC ratios for summer and fall had broader distributions than those for winter, suggesting that more differences in sources and chemical aging contributed to the OC levels in these seasons.

Generally, the WSOC/OC ratios obtained in this work were lower than those found at other urban and rural sites by previous studies. Decesari et al. [2001] showed seasonal variations in fine particles $\left(D_{p}<1.5 \mu \mathrm{m}\right)$ in the Po Valley, Italy, where WSOC accounted for 38 and $50 \%$ of OC in winter and summer, respectively. Kiss et al. [2002] measured WSOC $\left(\mathrm{D}_{\mathrm{p}}<1.5 \mu \mathrm{m}\right)$ by filter-based samplings to determine that WSOC accounted for $71 \%$ of OC on average at a rural site in Hungary from January to September 2000. Sullivan and Weber [2006a] reported that mean $\mathrm{WSOC} / \mathrm{OC}$ ratios in $\mathrm{PM}_{2.5}$ were $\sim 50$ and $60 \%$ in winter and summer, respectively, for urban measurements in St. Louis, MO and Atlanta, GA. At an urban site in Nanjing, China, WSOC accounted for $30 \%$ of OC for $\mathrm{PM}_{2.5}$ in winter [Yang et al., 2005]. More comprehensive summary of WSOC/OC ratios reported in the literature is found in Mader et al. [2004] and Jaffrezo et al. [2005].

The lower WSOC/OC ratios in the present study may reflect a larger contribution of local WIOC sources to the OC concentrations, compared to that in previous studies. For example, the mean WSOC value of $1.57 \mu \mathrm{gC} \mathrm{m}^{-3}$ for the entire period is similar to that $(1.98$ $\mu \mathrm{gC} \mathrm{m}^{-3}$ ) in urban Atlanta [Sullivan et al., 2006a], whereas the average WIOC value of 3.44 
$\mu \mathrm{gC} \mathrm{m}{ }^{-3}$ in urban Tokyo is much larger than that $\left(1.24 \mu \mathrm{gC} \mathrm{m}^{-3}\right)$ in Atlanta. This may have been due to the sampling site location in the vicinity of large urban sources of WIOC in Tokyo [Kondo et al., 2006a]. In fact, Ruellan and Cachier [2001] also observed low mean WSOC/OC values of $13 \%$ near a high-traffic road around Paris during summer and fall. This value is slightly lower than the winter WSOC/OC ratios reported in this work. A possible major source of WIOC in Tokyo is discussed in section 3.4. Another possibility is that WSOC formed by biogenic volatile organic compounds (VOCs) had little contributions to the observed WSOC in urban Tokyo. For example, in urban Atlanta in summer, measurements of chemically quantified functional groups of WSOC suggested that in addition to anthropogenic (mobile) sources, WSOC products of biogenic precursors contributed about 20 and $10 \%$ to WSOC and OC, respectively [Sullivan and Weber, 2006b]. However, these contributions were not evaluated in this study, because WSOC compounds were neither speciated into functional groups nor characterized at the molecular level.

\subsection{Comparison to the Derived SOC}

We now examine the relationship between the measured WSOC and derived SOC in the previous section for quantitative comparison of these two parameters. On average, the derived SOC accounted for $34 \pm 17,47 \pm 21$, and $37 \pm 20 \%$ of OC in winter, summer, and fall, respectively. Figure 6 shows the temporal variation of the measured WSOC and the derived SOC concentrations for each season. Scatter plots of WSOC and SOC are also shown in Figure 6. Temporal trends in WSOC and SOC were generally similar with highly positive correlations $\left(r^{2}=0.61-0.79\right)$ for all seasons. The slopes with $95 \%$ confidence intervals of the correlation in winter $(0.67 \pm 0.29)$, summer $(0.74 \pm 0.21)$, and fall $(0.73 \pm 0.22)$ were similar. In

contrast, WSOC was poorly correlated with POC $\left(\mathrm{r}^{2}=0.30-0.36\right)$ for each season. These 
results suggest that most of the SOC was associated with the WSOC measured at the present study. It is interesting to note that the average WSOC/SOC ratios tended to be smaller than 1 for all the seasons, even if the uncertainties in the SOC estimates (section 2.5) are taken into account. This may suggest that not all the SOC compounds were necessarily water-soluble; some SOC compounds are considered to still have large carbon-hydrogen functional groups, leading to insolubility.

Kondo et al. [2006b] compared the measured WSOC with oxygenated organic aerosols (OOA), which may be a good approximation of secondary organic aerosol when there are no contributions from biomass burning. Organic aerosol was measured with an Aerodyne aerosol mass spectrometer (AMS; Aerodyne Research, Billerica, MA) at the same sampling site in winter and summer [Kondo et al., 2006b; Takegawa et al., 2005]. OOA and hydrocarbon-like organic aerosols (HOA) were quantified separately from AMS mass spectral time series based on custom principal component analysis by using a newly developed algorithm by Zhang et al [2005]. Kondo et al. [2006b] showed that the measured WSOC was highly correlated $\left(\mathrm{r}^{2}=0.87-0.93\right)$ with OOA, indicating that WSOC and OOA represent a very similar set of chemical species in the aerosol. They also quantified total carbon concentrations in OOA (defined as OOC) derived from the OOA mass spectra, showing that $\sim 88 \%$ of OOC is WSOC (i.e., WSOC/OOC $\sim 88 \%$ ) at the same sampling site. Their result is similar to our result showing that on average the WSOC/SOC ratio is estimated to be $\sim 71 \%$. More details of the quantitative comparisons between WSOC and OOA measured at the same sampling site are discussed in Kondo et al. [2006b]. In summary, the measured WSOC was likely associated with most of the SOC present in this study.

\subsection{Water-Insoluble Organic Carbon (WIOC)}


We now examine possible sources of WIOC, since WIOC accounts for a significant part of OC at the sampling site in urban Tokyo. The average WIOC concentrations ranged between 2.7 and $4.1 \mu \mathrm{gC} \mathrm{m}{ }^{-3}$ during the entire period. The fractions of WIOC in the OC concentrations were 81,65 , and $63 \%$ in winter, summer, and fall, respectively, in terms of carbon.

Scatter plots of WIOC and EC are shown in Figure 7 for each season. Generally, WIOC correlated well with EC during the entire period with $\mathrm{r}^{2}$ ranging between 0.62 and 0.76 . Moreover, WIOC also correlated with $\mathrm{CO}\left(\mathrm{r}^{2}=0.54-0.63\right.$; not shown $)$, which is often used as a tracer of motor vehicle emissions in urban areas [e.g., Harrison et al., 1997; Lim and Turpin, 2002]. Most WIOC in urban areas is likely composed of incomplete combustion products such as aliphatic hydrocarbons, long-chain ketones, alkanols, and polycyclic aromatic hydrocarbons (PAHs) [e.g., Simoneit et al., 2004]. In fact, WIOC observed at the same sampling site was positively correlated with a signal at $\mathrm{m} / \mathrm{z} 57$ of the AMS mass spectra [Kondo et al., 2006b], which is a fragment $\left(\mathrm{C}_{4} \mathrm{H}_{9}{ }^{+}\right)$typical of saturated hydrocarbon compounds mainly from combustion sources [Allan et al., 2003; Alfarra et al., 2004]. These results indicate that motor vehicle emissions significantly contributed to the observed WIOC at the sampling site.

The slope of the correlation between WIOC and EC was stable to within $\pm 10 \%$ for all the seasons (1.0-1.2). When the datasets were segregated by local time, the slopes showed diurnal changes, ranging from $0.90-1.09$ between 0000 and 1200 LT $\left(r^{2}=0.65-0.78\right)$ to 1.20-1.31 between 1200 and 2400 LT $\left(r^{2}=0.59-0.73\right)$ for all the seasons. The changes of the slopes reflect larger local emissions of EC relative to WIOC between 0000 and 1200 LT (Figure 4), which is due to the larger fraction of heavy-duty trucks in the early morning (0400-0800 LT) [Kondo et al., 2006a]. The slopes for the data between 1200 and 2400 LT are 
considered to have resulted from more efficient mixing of air masses influenced by emissions with different WIOC/EC ratios. The changes of the slopes depending on local time were within $\pm 18 \%$, which were not as large as those for the EC/CO ratios (by a factor of $\sim 2$ ) [Kondo et al., 2006a]. In addition to the good correlations between WIOC and EC, the correlation coefficients were higher than those for OC and EC $\left(r^{2}=0.48-0.52\right)$, suggesting that the WIOC measured in the current study was a direct marker of POC in the urban area.

\section{Conclusions}

Semicontinuous measurements of WSOC in $\mathrm{PM}_{1}$ were made in an urban area of Tokyo in January, August, and November 2004 using a PILS followed by online quantification of the WSOC every 6 min (i.e., 6 minute integrals) using a TOC analyzer. OC and EC were simultaneously measured using a semicontinuous thermal-optical carbon analyzer. The PILS measurements were compared to 12-hr integrated filter-based measurements. These two measurements agreed well to within $12 \%$. The WSOC concentrations and WSOC/OC ratios showed diurnal variations with peaks at 1200 to 1400 LT in summer and at 1400-1800 LT in winter. On average, the WSOC concentrations in Tokyo accounted for $20 \%$ in winter and $35 \%$ in summer and fall of the OC concentrations in terms of carbon mass. The maximum values of WSOC/OC reached 37 and $86 \%$ in winter and summer, respectively. The seasonal difference in frequency distributions of the WSOC/OC ratio suggests that the air masses sampled in summer and fall were more photochemically processed than those in winter.

The concentrations of secondary organic carbon (SOC) were estimated using the EC-tracer method. The $\mathrm{NO}_{\mathrm{x}} / \mathrm{NO}_{\mathrm{y}}$ ratios and $\mathrm{CO}$ mixing ratios were used to determine the $\mathrm{OC} / \mathrm{EC}$ emission ratio from combustion sources. The mass concentrations of WSOC showed highly positive correlations with those of the estimated SOC $\left(r^{2}=0.70-0.79\right)$. The 
WSOC/SOC ratios (linear regression slopes) ranged from 0.67 to 0.75 . In contrast, the measured WSOC showed poor correlations with POC $\left(\mathrm{r}^{2}=0.30-0.36\right)$ throughout the study periods. These results suggest that most of the measured WSOC in this study was associated with SOC.

The average WIOC/EC ratios (linear regression slopes) observed in Tokyo were nearly constant throughout the three seasons (1.0-1.2). WIOC correlated well with EC and CO, indicating that motor vehicle emissions significantly contributed to the observed WIOC. 


\section{Definitions:}

EC: elemental carbon $\left(\mu \mathrm{gC} \mathrm{m}{ }^{-3}\right)$

HOA: hydrocarbon-like organic aerosol $\left(\mu \mathrm{g} \mathrm{m}^{-3}\right)$

OC: organic carbon $\left(\mu \mathrm{gC} \mathrm{m}{ }^{-3}\right)$

OOA: oxygenated organic aerosol $\left(\mu \mathrm{g} \mathrm{m}^{-3}\right)$

POC: primary organic aerosol $\left.(\mu \mathrm{gC} \mathrm{m})^{-3}\right)$

SOC: secondary organic carbon $\left(\mu \mathrm{gC} \mathrm{m} \mathrm{m}^{-3}\right)$

WIOC: water-insoluble organic carbon, WIOC $=$ OC - WSOC $\left(\mu \mathrm{gC} \mathrm{m}{ }^{-3}\right)$

WSOC: water-soluble organic carbon $\left(\mu \mathrm{gC} \mathrm{m} \mathrm{m}^{-3}\right)$

Acknowledgments. The authors thank A. Sullivan for providing the information on the PILS measurements. We also thank T. Watanabe and T. Nakajima for their help in the filter-based measurements of WSOC. This research was funded by the Japanese Ministry of Education, Culture, Sports, Science and Technology (MEXT) and the Japanese Science and Technology Agency (JST). 


\section{References}

Alfarra, M. R., H. Coe, J. D. Allan, K. N. Bower, H. Boudries, M. R. Canagaratana, J. L. Jimenez, J. T. Jayne, A. A.Garforth, S. Li, and D. R. Wosnop (2004), Characterization of Urban and Rural Organic Particulate in the Lower Fraser Valley using Two Aerodyne Aerosol Mass Spectrometers, Atmos. Environ., 38(1): 5745-5758.

Allan, J. D., J. L. Jimenez, P. I. Williams, M. R. Alfarra, K. N. Bower, J. T. Jayne, H. Coe, and D. R. Worsnop (2003), Quantitative Sampling using an Aerodyne Aerosol Mass Spectrometer, 1, Techniques of Data Interpretation and Error Analysis. J. Geophys. Res. 108:4090, doi:10.1029/2002JD002358.

Allen, G. A.., J. Lawrence, and P. Koutrakis (1999), Field validation of a semi-continuous method for aerosol black carbon (aethalometer) and temporal patterns of summertime hourly black carbon measurements in southwestern PA, Atmos. Environ., 33, 817-823.

Bae, M.-S., J. J. Schauer, J. T. DeMinter, J. R. Turner, D. Smith, and R. A. Cary (2004), Validation of a Semi-Continuous Instrument for Elemental Carbon and Organic Carbon using a Thermal-Optical Method, Atmos. Environ., 38, 2885-2893.

Birch, M. E., and R. A. Cary (1996), Elemental Carbon-Based Method for Monitoring Occupational Exposures to Particulate Diesel Exhaust, Aerosol Sci. Tech., 25, 221-241.

Cabada, J. C., S. N. Pandis, R. Subramanian, A. L. Robinson, A. Polidori, and B. Turpin (2004), Estimating the Secondary Organic Aerosol Contribution to $\mathrm{PM}_{2.5}$ using the EC Tracer Method, Aerosol. Sci. Technol., 38, 140-155.

Cooke, W. F., C. Liousse, H. Cachier, and J. Feichter (1999), Construction of a $1^{\circ} \times 1^{\circ}$ fossil fuel emission data set for carbonaceous aerosol and implementation and radiative impact in the ECHAM4 model, J. Geophys. Res., 104(D18), 22,137-22,162.

Decesari, S., M. C. Facchini, E. Matta, S. Fuzzi, and E. Tagliavini (2000), Characterization of water-soluble organic compounds in atmospheric aerosol: A new approach, J. Geophys. Res., 105, 1481-1489.

Decesari, S., M. C. Facchini, E. Matta, F. Lettini, M. Mircea, S. Fuzzi, E. Tagliavini, and J.-P. Putaud (2001), Chemical features and seasonal variation of fine aerosol water-soluble organic compounds in the Po Valley, Italy, Atmos. Environ., 35, 3691-3699.

Eatough, D. J., A. Wadsworth, D. A. Eatough, J. W. Crawford, L. D. Hansen, and E. A. Lewis, (1993), A multiple system, multi-channel diffusion denuder sampler for the determination of fine-particulate organic material in the atmosphere, Atmos. Environ., 27A, 1213-1219.

Facchini, M. C., M. Mircea, S. Fuzzi, and R. J. Charlson, (1999), Cloud albedo enhancement by surface-active organic solutes in growing droplets, Nature, 401, 257-259.

Harley, R. A., L. C. Marr, J. K. Lehner, and S. N. Giddings (2005), Changes in motor vehicle emissions on diurnal to decadal time scales and effects on atmospheric composition, 
Environ. Sci. Technol. 39, 5356-5362.

Harrison, R. M., A. R. Deacon, M. R. Jones and R. S. Appleby (1997), Sources and processes affecting concentrations of $\mathrm{PM}_{10}$ and $\mathrm{PM}_{2.5}$ particulate matter in Birmingham (U.K.), Atmos. Environ., 31, 4103-4117.

Havers, N., P. Burba, J. Lambert, and D. Klockow (1998), Spectroscopic characterization of humic-like substances in airborne particulate matter, J. Atmos. Chem., 29, 45-54.

Jacobson, M. C., H.-C. Hansson, K. L. Noone, and R. J. Charlson (2000), Organic atmospheric aerosols: Review and state of the science, Rev. Geophys., 38, 267-294.

Jaffrezo, J.-L. G. Aymoz, C. Delaval, and J. Cozic (2005), Seasonal variations of the water soluble organic carbon mass fraction of aerosol in two valleys of the French Alps, Atmos. Chem. Phys., 5, 2809-2821.

Kawamura, K. and F. Sakaguchi (1999), Molecular distributions of water soluble dicarboxylic acids in marine aerosols over the Pacific Ocean including tropics, J. Geophys. Res., 104, 3501-3509.

Kawamura, K., and O. Yasui (2005), Diurnal changes in the distribution of dicarboxylic acids, ketocarboxylic acids and dicarbonyls in the urban Tokyo atmosphere, Atmos. Environ., 39, 1945-1960.

Kiss, G., B. Varga, I. Galambos, and I. Ganszky (2002), Characterization of water-soluble organic matter isolated from atmospheric fine aerosol, J. Geophys. Res., 107, 8339, doi:10.1029/2001JD000603.

Kondo, Y., S. Kawakami, M. Koike, D. W. Fahey, H. Nakajima, N. Toriyama, M. Kanada, Y. Zhao, G. W. Sachse, and G. L. Gregory (1997), The performance of an aircraft instrument for the measurement of $\mathrm{NO}_{\mathrm{y}}$, J. Geophys. Res., 102, 28,663-28,671.

Kondo, Y., Y. Komazaki, Y. Miyazaki, N. Moteki, N. Takegawa, M. Nogami, S. Deguchi, M. Fukuda, T. Miyakawa, Y. Morino, D. Kodama, M. Koike, H. Sakurai, and K. Ehara (2006a), Temporal variations of elemental carbon in Tokyo, J. Geophy. Res., in press.

Kondo, Y., Y. Miyazaki, N. Takegawa, T. Miyakawa, R. J. Weber, J. L. Jimenez, Q. Zhang, and D. R. Worsnop (2006b), Oxygenated and water soluble organic aerosols in Tokyo, submitted to J. Geophy. Res.

Lim, H. J., and B. J. Turpin (2002), Origins of primary and secondary organic aerosol in Atlanta: Results of time-resolved measurements during the Atlanta supersite experiment, Environ. Sci. Technol., 36, 4489-4496.

Mader B. T., J. Z. Yu, J. H. Xu, Q. F. Li, W. S. Wu, R. C. Flagan, and J. H. Seinfeld (2004), Molecular composition of the water\&hyphen;soluble fraction of atmospheric carbonaceous aerosols collected during ACE-Asia, J. Geophys. Res., 109, D06206, doi:10.1029/2003JD004105. 
Mayol-Bracero O. L., P. Guyon, B. Graham, G. Roberts, M. O. Andreae, S. Decesari, M. C. Facchini, S. Fuzzi, and P. Artaxo (2002), Water-soluble organic compounds in biomass burning aerosols over Amazonia, 2, Apportionment of the chemical composition and importance of the polyacidic fraction, J. Geophys. Res., 107 (D20), 8091, doi:10.1029/2001JD000522.

Novakov, T., and J. E. Penner (1993), Large contribution of organic aerosols to cloud-condensation-nuclei concentrations, Nature, 365, 823-826.

Orsini, D. A., Y. Ma, A. Sullivan, B. Sierau, K. Baumann, and R. J. Weber (2003), Refinements to the particle-into-liquid sampler (PILS) for ground and airborne measurements of water soluble aerosol composition, Atmos. Environ., 37, 1243-1259.

Riemer, N., H. Vogel, and B. Vogel (2004), Soot aging time scales in polluted regions during day and night, Atmos. Chem. Phys., 4, 1885-1893.

Ruellan, S., and H. Cachier (2001), Characterisation of fresh particulate vehicular exhausts near a Paris high flow road, Atmos. Environ., 35, 453-468.

Saxena, P., L. M. Hildemann, P. H. McMurry, and J. H. Seinfeld (1995), Organics alter hygroscopic behavior of atmospheric particles, J. Geophys. Res., 100, 18,755-18,770.

Saxena, P., L. and M. Hildemann (1996), Water-soluble organics in atmospheric particles: A critical review of the literature and application of thermodynamics to identify candidate compounds, J. Atmos. Chem., 24, 57-109.

Sempere, R., and K. Kawamura (1994), Comparative distributions of dicarboxylic acids and related polar compounds in snow, rain and aerosols from urban atmosphere, Atmos. Environ., 28, 449-459.

Simoneit, B. R. T., M. Kobayashi, M. Mochida, K. Kawamura, M. Lee, H.-J. Lim, B. J. Turpin, and Y. Komazaki (2004), Composition and major sources of organic compounds of aerosol particulate matter sampled during the ACE-Asia campaign, J. Geophys. Res., 109 D19S10, doi:10.1029/2004JD004598.

Sullivan, A. P., R. J. Weber, A. L. Clements, J. R. Turner, M. S. Bae and J. J. Schauer (2004), A method for on-line measurement of water-soluble organic carbon in ambient aerosol particles: Results from an urban site, Geophys. Res. Lett., 31, L13105, doi:10.1029/2004GL019681.

Sullivan, A. P., and R. J. Weber (2006a), Chemical characterization of the ambient organic aerosol soluble in water Part 1: Isolation of hydrophobic and hydrophilic fractions, $J$. Geophys. Res., 111, D05314, doi:10.1029/2005JD006485.

Sullivan, A. P., and R. J. Weber (2006b), Chemical characterization of the ambient organic aerosol soluble in water Part 2: Analysis of hydrophobic and hydrophilic fractions by size-exclusion chromatography with TOC detection, J. Geophys. Res., 111, D05315, 
doi:10.1029/2005JD006486.

Strader, R., F. Lurmann, and S. N. Pandis (1999), Evaluation of secondary organic aerosol formation in winter, Atmos. Environ., 33, 4849-4863.

Streets, D. G., T. C. Bond, G. R. Carmichael, S. D. Fernandes, Q. Fu, D. He, Z. Klimont, S. M. Nelson, N. Y. Tsai, M. Q. Wang, J.-H. Woo, and K. F. Yarber (2003), An inventory of gaseous and primary aerosol emissions in Asia in the year 2000, J. Geophys. Res., 108(D21), 8809, doi:10.1029/2002JD003093.

Takegawa, N., Y. Miyazaki, Y. Kondo, Y. Komazaki, T. Miyakawa, J. L. Jimenez, J. T. Jayne, D. R. Worsnop, J. Allan, and R. J. Weber (2005), Characterization of an Aerodyne Aerosol Mass Spectrometer (AMS): Intercomparion with other aerosol instruments, Aerosol Sci. Technol., 39:760-770.

Takegawa, N., T. Miyakawa, Y. Kondo, J. L. Jimenez, D. R. Worsnop, and M. Fukuda (2006), Seasonal and diurnal variations of submicron organic aerosol in Tokyo observed using of the Aerodyne Aerosol Mass Spectrometer, submitted to J. Geophy. Res.

Turpin, B. J., and J. J. Huntzicker (1991), Secondary formation of organic aerosol in the Los Angeles Basin: a descriptive analysis of organic and elemental carbon concentrations, Atmos. Environ., 25A, 207-215.

Turpin, B. J., and J. J. Huntzicker (1995), Validation of a semi-continuous instrument for elemental carbon and organic carbon using a thermal-optical method, Atmos. Environ., 29, 3527-3544.

Turpin, B. J., P. Saxena, and E. Andrews (2000), Measuring and simulating particulate organics in the atmosphere: problems and prospects, Atmos. Environ., 34, 2983-3013.

Wang, H., K. Kawamura, and D. Shooter (2005), Carbonaceous and ionic components in wintertime atmospheric aerosols froom two New Zealand cities: Implications for solid fuel combustion, Atmos. Environ., 39, 5865-5875.

Warneck, P. (2003), In-cloud chemistry opens pathway to the formation of oxalic acid in the marine atmosphere, Atmos. Environ., 26, 2423-2427.

Weber, R. J., D. Orsini, Y. Daun, Y. -N. Lee, P. J. Klotz, and F. Brechtel (2001), A particle-into-liquid collector for rapid measurement of aerosol bulk chemical composition, J. Aerosol Sci.Technol., 35, 718-727.

Yang, H., J. Z. Yu, S. S. H. Ho, J. Xu, W-S. Wu, C. H. Wan, X. Wang, X. Wang and L. Wang (2005), The chemical composition of inorganic and carbonaceous materials in $\mathrm{PM}_{2.5}$ in Nanjing, China, Atmos. Environ., 39, 3735-3749.

Zappoli, S., A. Andracchio, S. Fuzzi, M. C. Facchini, A. Gelencsér, G. Kiss, Z. Krivácsy, Á. Molnár, E. Mészáros, H. -C. Hansson, K. Rosman, and Y. Zebühr (1999), Inorganic, organic and macromolecular components of fine aerosol in different areas of Europe in 
relation to their water solubility, Atmos. Environ., 33, 2733-2743.

Zhang Q., M. R. Alfarra, D. R. Worsnop, J. D. Allan, H. Coe, M. R. Canagaratna, and J. L. Jimenez (2005), Deconvolution and quantification of hydrocarbon-like and oxygenated organic aerosols based on aerosol mass spectrometry, Env. Sci. Tech., 39, 4948-4952, doi:10.1021/es0485681.

M. Fukuda, Y. Komazaki, Y. Kondo, Y. Miyazaki, and N. Takegawa, Research Center for Advanced Science and Technology, University of Tokyo, 4-6-1 Komaba, Meguro-ku, Tokyo 153-8904, Japan. (fukuda@atmos.rcast.u-tokyo.ac.jp; komazaki@atmos.rcast.u-tokyo.ac.jp; kondo@atmos.rcast.u-tokyo.ac.jp; yuzom@atmos.rcast.u-tokyo.ac.jp; takegawa@atmos.rcast.u-tokyo.ac.jp)

K. Kawamura, M. Mochida and K. Okuzawa, Institute of Low Temperature Science, Hokkaido University, Sapporo, Japan. (kawamura@lowtem.hokudai.ac.jp; mochida@pop.lowtem.hokudai.ac.jp; kazuhiro@pop.lowtem.hokudai.ac.jp) R. J. Weber, School of Earth and Atmospheric Sciences, Georgia Institute of Technology, Atlanta, GA, USA. (rweber@eas.gatech.edu) 


\section{Figure Captions}

Figure 1. (a) Time series of the PILS-WSOC (shaded line) and integrated filter measurements (solid bars) during 9-15 August 2004. The solid bars in the time series plot represent the sampling time ( $\sim 12 \mathrm{hr})$ for collecting particles. (b) A scatter plot of these two measurements with the linear regression line forced through zero (solid line). The individual PILS-WSOC data values were merged into the filter sampling periods. The dashed line indicates 1:1 correspondence.

Figure 2. Scatter plots of OC versus EC for all measurements (shaded circles) and the data used for estimating primary OC and EC concentrations (open circles) for each study period. The solid line is the linear regression slope for the primary OC and EC concentrations.

Figure 3. Time series plots of OC (solid squares), WSOC (solid circles), and EC (open triangles) for (a) winter, (b) summer, and (c) fall 2004 in Tokyo.

Figure 4. Diurnal variations of measured WSOC, OC, WSOC/OC, WIOC, EC, and CO for each season. Values shown are medians for each 2-hr bin, and the bars for each value represent $1-\sigma$ values.

Figure 5. Frequency distributions of the WSOC/OC ratios for each season.

Figure 6. Time series plots of the measured WSOC (solid circles with lines) and the estimated SOC (shaded area) for winter, summer, and fall 2004 (left panels). The shaded area represents uncertainties associated with the estimate for slopes of $(\mathrm{OC} / \mathrm{EC})_{\text {prim }}$ (see text). Scatter plots of WSOC and SOC are also shown (right panels).

Figure 7. Scatter plots of WIOC versus EC mass concentrations for winter, summer, and fall 2004. Linear regression fit parameters (slope and $r^{2}$ ) for the correlations are also shown 
for each season. Solid and open circles indicate the data obtained between 0000-1200 LT and 1200-2400 LT, respectively. 
Table 1. Estimated parameters for the linear fit of POC and EC concentrations.

\begin{tabular}{cccccc}
\hline & $\begin{array}{c}\text { Number } \\
\text { of data } \\
\text { values }\end{array}$ & {$[\mathrm{OC} / \mathrm{EC}]_{\mathrm{prim}}{ }^{\mathrm{a}}$} & $\begin{array}{c}\mathrm{OC}-\mathrm{EC} \\
\text { Correlation } \\
\text { coefficient }\left(\mathrm{r}^{2}\right)\end{array}$ & $\mathrm{NO}_{\mathrm{x}} / \mathrm{NO}_{\mathrm{y}}$ & $\mathrm{CO}(\mathrm{ppbv})$ \\
\hline Winter (Jan.-Feb. 2004) & 42 & $\begin{array}{c}1.46 \\
(1.34-1.58)\end{array}$ & 0.76 & 0.90 & 700 \\
\hline Summer (Aug. 2004) & 15 & $\begin{array}{c}1.36 \\
(1.24-1.48)\end{array}$ & 0.90 & 0.80 & 400 \\
\hline Fall (Nov. 2004) & 43 & $\begin{array}{c}1.33 \\
(1.20-1.46)\end{array}$ & 0.72 & --- & 700 \\
\hline
\end{tabular}

${ }^{\mathrm{a}}$ The $95 \%$ confidence interval is in parentheses.

${ }^{\mathrm{b}}$ Selection criteria for $\mathrm{OC}$ and EC concentrations influenced by anthropogenic primary emissions.

Table 2. Mean values and \pm standard deviation of $\mathrm{PM}_{1}$ WSOC, WIOC, OC, EC, and the WSOC/OC ratios for the three study periods in Tokyo.

\begin{tabular}{cccccc}
\hline & $\begin{array}{c}\text { WSOC, } \mu \mathrm{gC} \\
\mathrm{m}^{-3}\end{array}$ & WIOC, $\mu \mathrm{gC} \mathrm{m}^{-3}$ & OC, $\mu \mathrm{gC} \mathrm{m}^{-3}$ & $\mathrm{EC}, \mu \mathrm{gC} \mathrm{m}{ }^{-3}$ & WSOC/OC \\
\hline $\begin{array}{c}\text { Winter (Jan.-Feb. } \\
\text { 2004) }\end{array}$ & $1.05 \pm 0.91$ & $4.05 \pm 1.99$ & $5.00 \pm 2.78$ & $2.46 \pm 1.33$ & $0.19 \pm 0.08$ \\
\hline Summer (Aug. 2004) & $1.28 \pm 1.18$ & $2.70 \pm 1.45$ & $3.98 \pm 2.68$ & $1.69 \pm 1.17$ & $0.35 \pm 0.15$ \\
\hline Fall (Nov. 2004) & $2.38 \pm 1.84$ & $3.57 \pm 2.30$ & $5.95 \pm 2.37$ & $3.52 \pm 2.32$ & $0.37 \pm 0.14$ \\
\hline
\end{tabular}


Figure 1.
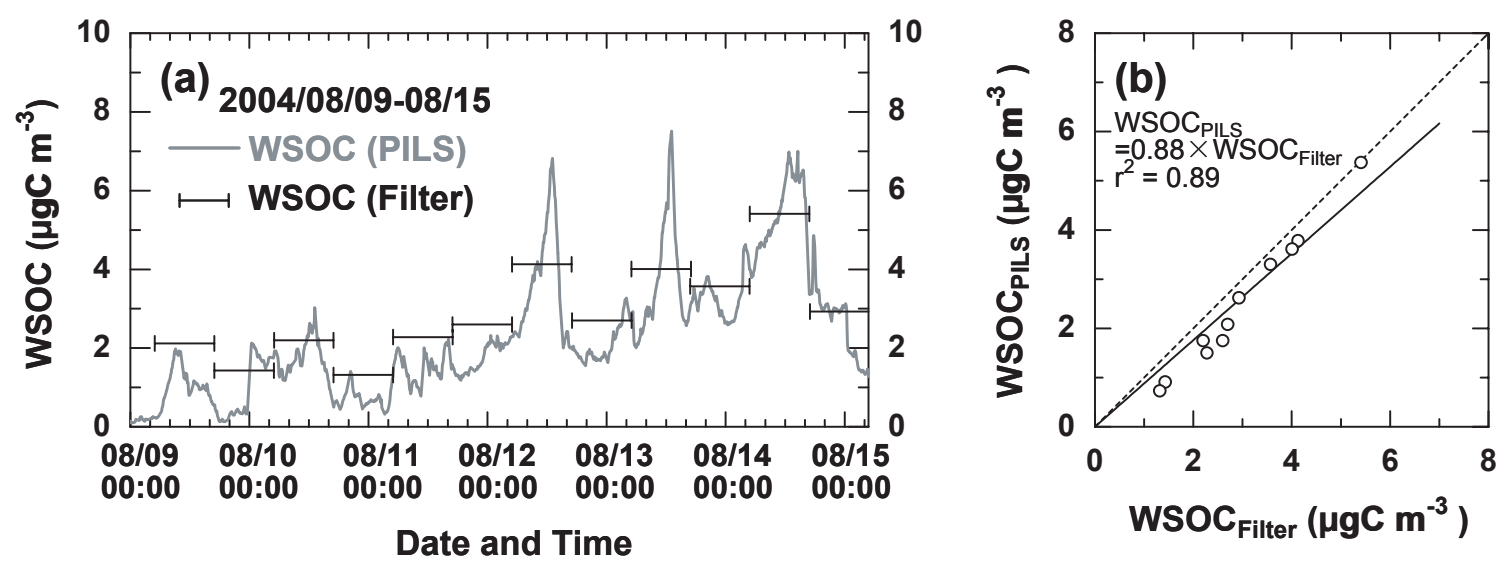
Figure 2.
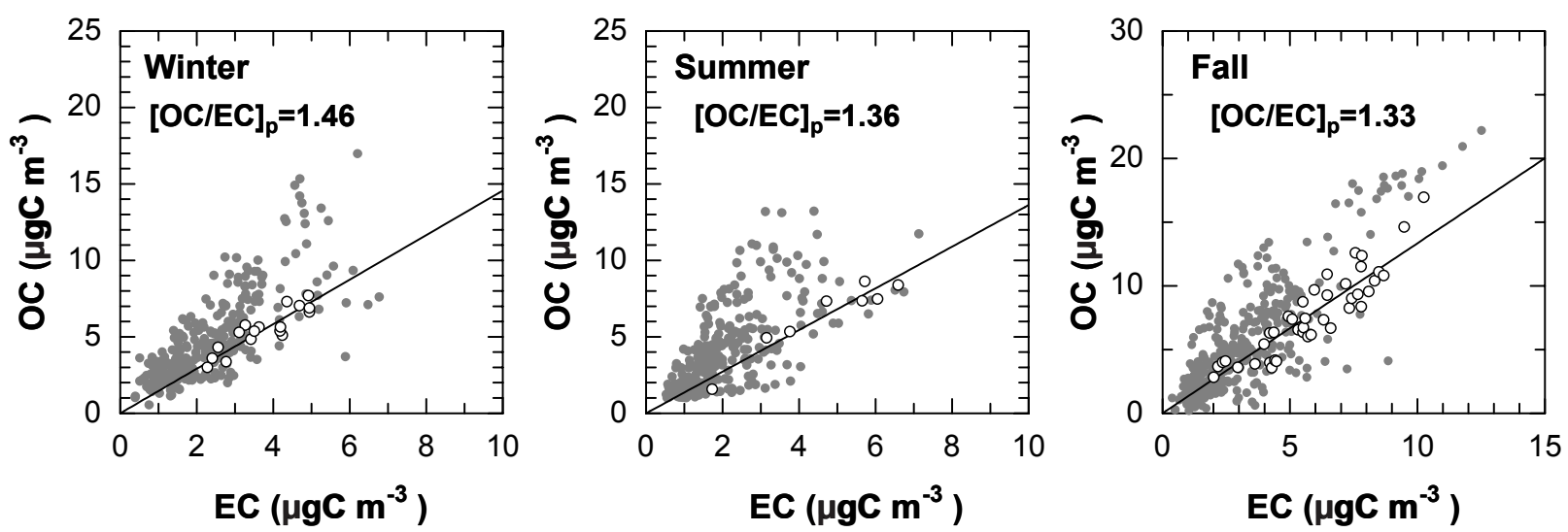
Figure 3.

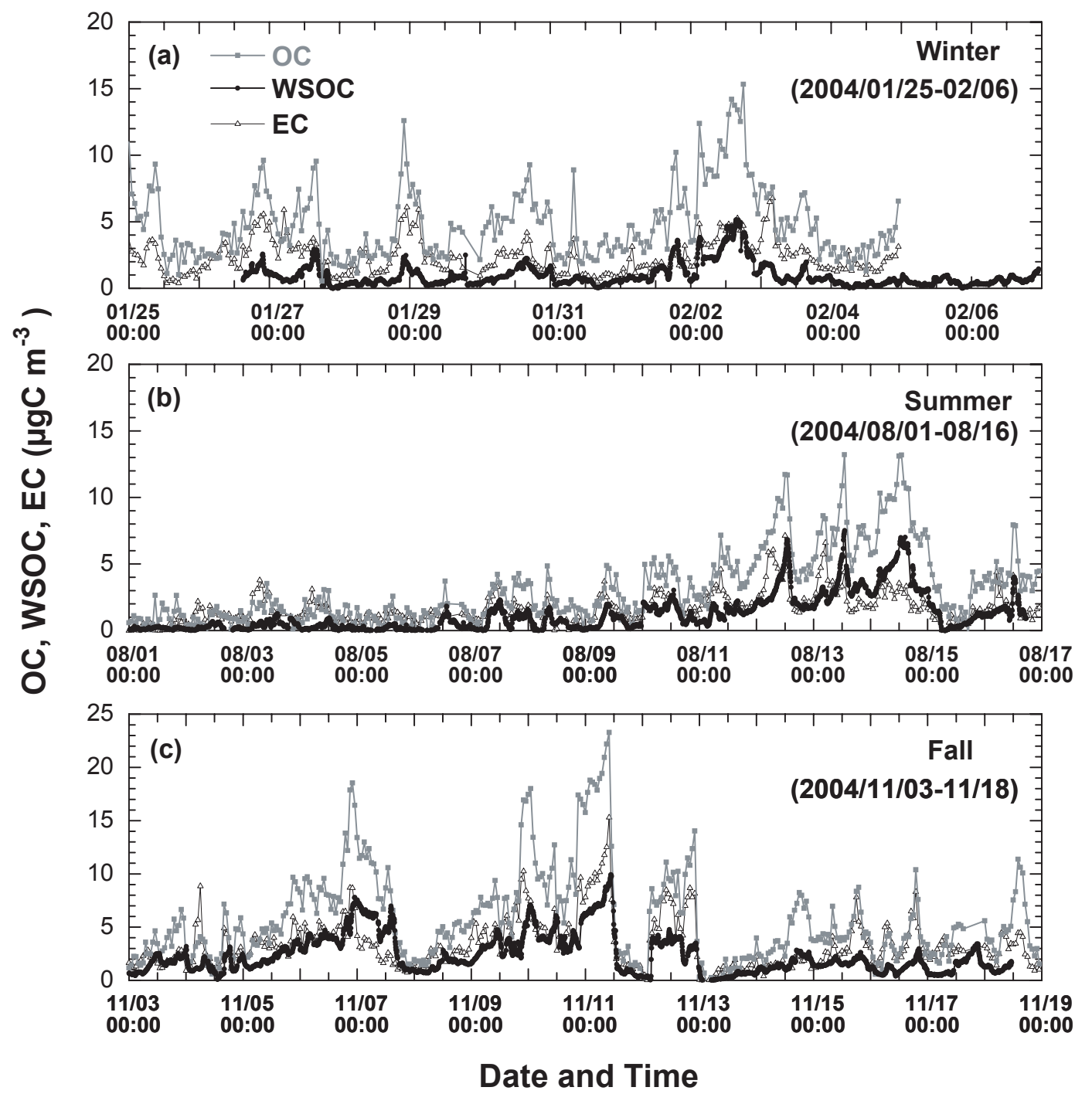


Figure 4.

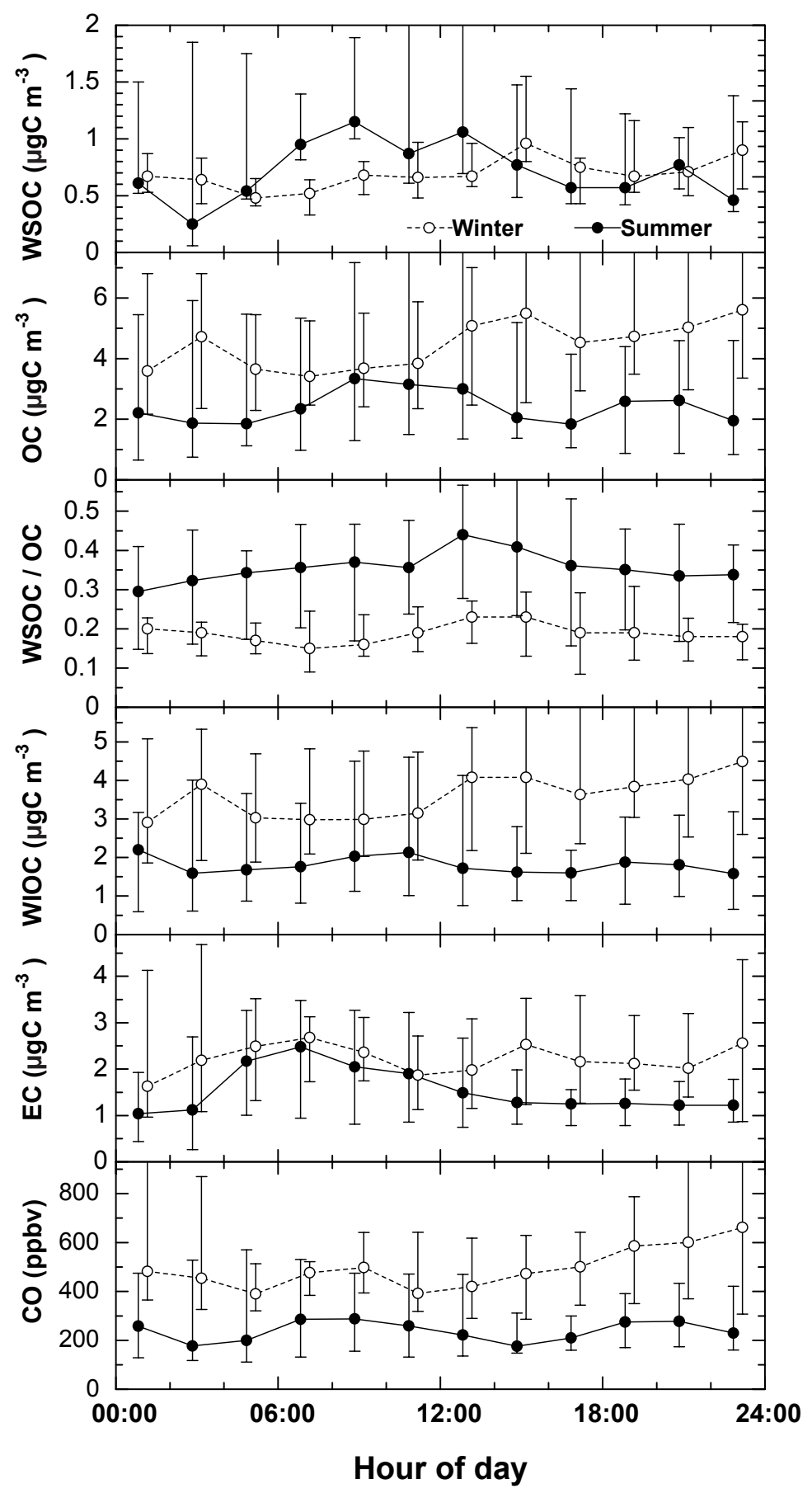


Figure 5.

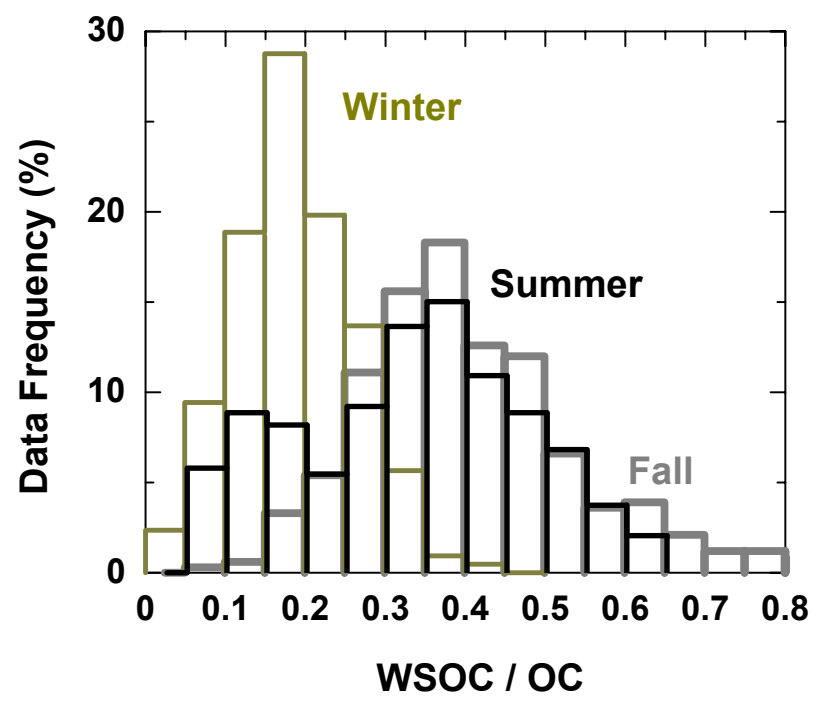


Figure 6.
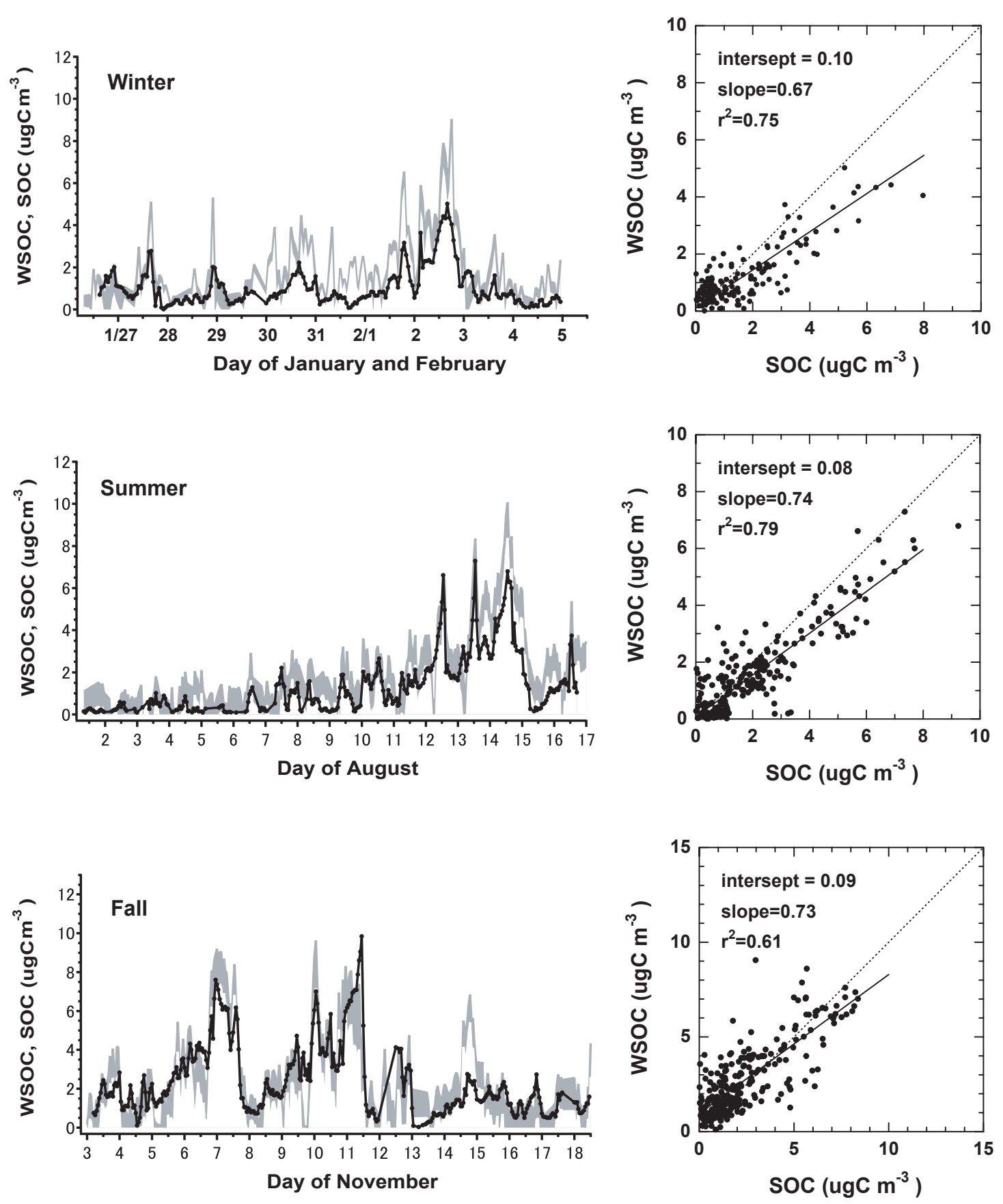
Figure 7.
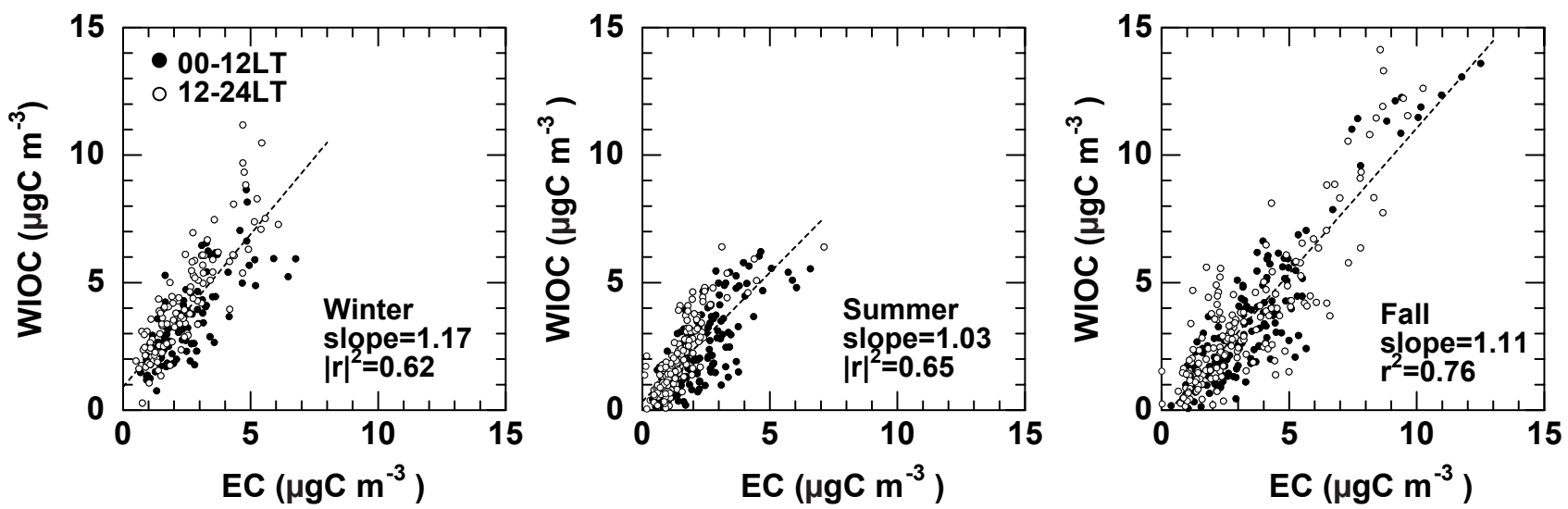